\title{
A Discounted Threat: Environmental Impacts of the Livestock Industry
}

\author{
Leanne Bourgeois* \\ Grant MacEwan University, Canada
}

\begin{abstract}
This article provides an overview of the environmental effects of the livestock industry. Current industry practice, specifically the proliferation of concentrated animal feeding operations as the primary means of production, has left farreaching ecological consequences in its wake. Animal agriculture is implicated in numerous environmental threats including rising greenhouse gas emissions (particularly through release of nitrous oxide and methane, in addition to carbon dioxide), overconsumption of water for both live animals and feed crops, and decreased water quality. Furthermore, localized pollution owing to significant animal waste has contaminated many regions and compromised human health. Alterations of land use and the resulting loss of biodiversity are also of major concern. The problem has expanded as developing countries' demand for these products grows - however, the issue has tended not to be a focal point of environmental debate. This article details the environmental destruction wrought by current practices, while outlining recommendations for reducing the environmental toll at both the individual and systemic level.
\end{abstract}

\section{Introduction}

Anthropogenic effects on the environment have increasingly become a major concern in the $21^{\text {st }}$ century, and efforts to mitigate these effects are of critical importance. The industrialization era in the middle of the $20^{\text {th }}$ century accelerated the 
extraction of natural resources for the production of goods and services, and has since been the subject of environmental contention. Extraction of oil and natural gas and the subsequent burning of fossil fuels have received the most criticism for their role in global warming. Similarly, production of plastics and other non-biodegradable material is a recognized source of pollution. Although these factors contribute significantly to environmental degradation, they have been given a disproportionate amount of attention when compared to the pervasive and wide-ranging environmental consequences of animal agriculture. The livestock industry includes both extensive pasture based farming, and intensive, factory-farm production, the latter having a far greater impact on the environment.

Factory farms, otherwise known as Concentrated Animal Feeding Operations (CAFOs), are an economically efficient, energy intensive method of rearing animals for human consumption, and are characterized by dense populations of farmed animals kept in warehouses rather than in pasture. CAFOs originated in the 1950s and currently account for the majority of the meat produced in North America and Europe (FAO, 2006, pg.32). The proportion of factory-farmed meat is steadily increasing in the developing world as the demand for meat intensifies and markets in these countries respond accordingly (Pluhar, 2009, p. 456). In total, approximately 56 billion terrestrial animals are reared for consumption each year (Koneswaran \& Nierenburg, 2008, p. 578) - eight times the size of the human population - and the livestock population is expected to double by the year 2050 (Ilea, 2009, p. 153). Factory farms enable high outputs of meat production at relatively low inputs of cost and labour. Although economically favourable, this intense farming method produces extensive amounts of waste and hazardous emissions that are costly to the environment (Patel \& Centner, 2010, p. 13).

More recently, environmentalists have come to associate the practice of factory farming with rising greenhouse gas emissions, pollution, environmental degradation and loss of biodiversity. Direct correlations can be shown between the abundance of animal waste produced and high concentrations of pollutants and greenhouse gases emitted at each site. A larger impact can be attributed to the indirect environmental toll created through feed crop production. This paper outlines the environmental ramifications of the livestock industry by highlighting the importance of this issue, and the need for an increase in public concern. 


\section{Results}

Atmosphere. In total, the livestock industry accounts for 18 percent of anthropogenic greenhouse gas emissions (FAO, 2006, p. 112). Carbon dioxide, methane, and nitrous oxide are the three main constituents that account for this value. Carbon dioxide $\left(\mathrm{CO}_{2}\right)$ has the most significant impact on global warming due to the large quantities emitted primarily through burning fossil fuels (Koneswaran \& Nierenburg, 2008, p. 579). Each year, factory farms contribute 9 percent of the total $\mathrm{CO}_{2}$ emissions, emitting 41 million tonnes of $\mathrm{CO}_{2}$ for feed crops, 90 million tonnes for farm operations, 2.4 billion tonnes as a result of deforestation and 28 million tonnes from cultivated soils (p. 579). Although atmospheric concentrations of nitrous oxide and methane are considerably lower than carbon dioxide, their contribution to global warming is substantial. The global warming potentials of methane and nitrous oxide are 23 and 296 times greater, respectively, than that of carbon dioxide and therefore can significantly alter the global temperature, despite smaller emissions (Mann \& Kump, 2010, p. 29). Animal manure and synthetic fertilizers produce excessive amounts of nitrogen, which amount to 65 percent of total anthropogenic nitrogen released into the atmosphere (FAO, 2006, p. 114). Methane is produced in large part due to enteric fermentation of ruminants, and is released by way of animal flatulence as well as manure. These processes total 35-40 percent of human-induced methane emissions, measuring 86 million tonnes worldwide (Koneswaran \& Nierenberg, 2008, p. 580). All told, the livestock sector exerts a substantial influence on global climate, outpacing even the total global emissions of human transportation.

Pollution is another major issue surrounding the pervasive practice of factory farming. In the United States, over 133 million tonnes of manure is produced each year (Burkholder et al., 2007, p. 308). Some of this manure is treated and used as fertilizer, while most of it is stored in large waste lagoons. In either case, a number of toxic gases are released containing chemical compounds such as ammonia and hydrogen sulfide (Heederik et al., 2007, p. 298). The livestock industry contributes 64 percent of anthropogenic ammonia, leading to acidification of ecosystems and to production of acid rain. The distinct odour of animal waste can be attributed to hydrogen sulfide, a powerful and poisonous gas (p. 298). Other pollutants include bacterial species, antibiotic residues and endotoxins, all of which have an impact on surrounding communities (Mirabelli et al., 2006, p. 591). Studies have confirmed a heightened incidence of respiratory symptoms, headaches, diarrhea, burning eyes and sore throats occuring among neighbouring communities. Research has also demonstrated a decreased quality of life among residents living near these operations (p. 591). 
Water. Many components of the livestock industry have a considerable influence on water quality and availability. Industrial agriculture uses approximately 70 percent of available freshwater, of which more than $8 \%$ is allocated for feed crop irrigation (Henning, 2011, p. 8). Perhaps the most direct and destructive environmental consequence of factory farming is water pollution. As mentioned, livestock produces significant amounts of manure, usually more than a single farm can manage. Often, runoff occurs in fields where manure was applied as fertilizer, or waste lagoons overflow due to heavy rainfalls or ruptures (Burkholder et al., 2007, p. 308). Typically, the run-off makes its way into local waterways or passes through the soil into groundwater (Mallin \& Cahoon, 2003, p. 370). Manure is rich in compounds of nitrogen, phosphorus, and ammonia. When excessive amounts of these compounds are added to the environment, they can lead to noxious algal blooms, causing eutrophication in both fresh and coastal waters, killing fish, and destroying coral reefs (p. 371). Manure is also composed of a variety of parasites, bacteria, viruses, and antibiotic residues that can pollute water supplies, thereby causing many human health issues such as gastrointestinal distress, infections (Burkholder et al., 2007, p. 308) and large-scale bacterial disease outbreaks (Mallin \& Cahoon, 2003, p. 380).

Land Use Changes. Concentrated animal feeding operations constitute the largest anthropogenic use of land (FAO, 2006, p. 270). The proportion of land utilized for the production of meat dwarves that of any other industry. CAFOs convert wooded areas to grazing fields or cropland on a large scale; one-third of the Earth's land surface is used for animal agriculture and approximately 33 percent of the total available agricultural land is used for feed crops (p. 271). This is particularly troubling in Latin America, where deforestation of the Amazon Rain Forest - one of Earth's most biologically rich areas has resulted in the largest net loss of forested areas for grazing and feed crops (p. 91).

Biodiversity. The biosphere is currently undergoing a $6^{\text {th }}$ mass extinction (Barnosky et al., 2011, p. 51). This widespread loss is owed to rising global temperatures, habitat destruction, pollution, and overexploitation (Primack, 2010, pp.196-202, 211-212, 215243). Loss of species is currently taking place at a rate 50-500 times higher than historical extinction rates recorded by the fossil record (Woodruff, 2001 p. 5471). The livestock industry has a major influence in perpetuating such calamitous events, due to its contribution to climate change, pollution, land degradation, and facilitation of invasive species. Of the 825 terrestrial ecosystems around the world, 306 are reported by the World Wildlife Organization to be threatened as a consequence of factory farming (FAO, 2006, p. 215). Conservation International has implicated the livestock industry in negatively impacting more than half of the most biologically rich regions in the world (p. 215). 


\section{Discussion}

The livestock industry's effects on our current environmental condition has been largely underappreciated or ignored. The United Nations has declared concentrated animal feeding operations to be "one of the top two or three most significant contributors to the most serious environmental problems, at every scale from local to global" (FAO, 2006, p. 22). Yet, CAFOs are marginalized in public environmental debate. The broad impact of factory farming on global climate change has not been given its due attention. Factory farming contributes to large changes in the nitrogen, carbon and methane cycles, all of which operate on a global scale. Carbon dioxide is emitted at each stage of meat production - indirectly by deforestation and cultivation of feed crops, and directly from on-site energy consumption and transport (Koneswaran \& Nierenberg, 2008, p. 579). To some extent, emphasis on the reduction of carbon emissions has overshadowed the importance of nitrogen and methane emissions on climate change. Factory farms contribute 65 percent of the total anthropogenic nitrogen emitted, along with 40 percent of atmospheric methane. It is troubling that these issues have only played a minor role in climate change awareness, considering that changes in the nitrogen and methane cycles have a greater impact on our environment than carbon (p. 578). With its complicity in global warming, the livestock sector can be held partly accountable for glacial melt, increased sea-levels, rising ocean temperature, extreme weather events, habitat loss, displacement, and species extinction (Kump et al., 2010, pp. 321-327, 364-372).

The availability of freshwater and degradation of water reserves is an ever-increasing global concern. Water scarcity is increasing - 64 percent of the world population is expected to live in water-stressed areas by 2025 (FAO, 2006, p. 24). The livestock industry contributes substantially, albeit indirectly, to global water storage, and is therefore usually overlooked in the planning of water-conservation strategies. Of all water consumed worldwide, 70 percent is used in agricultural processes (Henning, 2011, p. 8). Of these agricultural processes, one third is designated to feed crops. Thus, most of the freshwater used in agriculture is directed toward sustaining livestock production. To illustrate a sense of perspective, it requires 100 times more water to produce $1 \mathrm{~kg}$ of animal protein compared to $1 \mathrm{~kg}$ of plant protein (p. 8), when all levels of production are considered. The scope of the water problem is further highlighted by the Food and Agriculture Organization of the United Nations, who identify the livestock industry as "the largest sectoral source of water pollution, contributing to eutrophication, "dead" zones in coastal areas, degradation of coral reefs, human health problems, [and] emergence of antibiotic resistance" (p. 24). The majority of water used for livestock re- 
enters the environment in the form of wastewater and manure, limiting the availability of fresh water.

The expansion of feed crops and grazing areas into natural ecosystems is causing negative environmental impacts. Land use change contributes to many global issues including climate change, which is exacerbated by the loss of carbon sequestering vegetation, in addition to water depletion. The latter issues also impact upon biodiversity and the upward trend in extinction rates (FAO, 2006, p. 185). Biodiversity plays an integral role in fully functioning and healthy ecosystems, which in turn benefit humans through the services they provide. These services, aptly named "ecosystem services," include processes involved in air and water purification, carbon sequestration, waste decomposition, disease prevention, and pharmaceuticals (Primack, 2010, p. 81), to name only a few. These services often go unnoticed or are taken for granted, and thus habitat destruction is perpetuated for immediate and measurable economic gains. The anthropogenic effect on species extinction is undisputed within the scientific community. However, it is infrequently suggested that the livestock industry could be the root of this predicament.

In order to improve the livestock industry's present position as a significant environmental liability, an extensive review of the food production methods would be required. This would involve a complete re-working of our food system, at both the level of consumer behaviors and methods of production. Governments would need to implement tougher regulations on emissions and pollution, as well as enforce accurate pricing in full consideration of water scarcity and exploitation of ecosystem services (FAO, 2006 p. 24). Consumers could initiate change by eating a more plant-based diet or selectively buying meat products from producers with a smaller environmental footprint. More sustainable methods of production, such as extensive pasture based farming, can only prosper if the over-consumption of meat and inflated demand begin to show a reverse.

The environmental impact of the livestock industry is unprecedented, as it contributes to dire environmental concerns. Authorities on the subject consider the industry to be among the top three contributors to global warming, the largest sectoral source of water pollution, and the leading cause of biodiversity loss through deforestation and land degradation. Despite the scale of this issue, it frequently goes under the radar of popular environmental concern, and is seldom in the spotlight of media. In order to alleviate this environmental burden on the Earth's system, the livestock industry's impact on the environment needs to be brought to the forefront of 
public concern and translated, on the part consumers and policy makers, into meaningful actions designed to conserve the biosphere.

\section{Acknowledgements}

I would like to thank Jordan Olischefski and Mike Kropiniski for their meticulous review and thoughtful input.

*W riter: Leanne Bourgeois is a 4th year student at Grant MacEwan University studying Biology and Earth \& Atmospheric science.

\section{References}

Barnosky, A. D., Matzke, N., Tomiya, S., Wogan, G. O. U., Swartz, B., Quental, T. B., Marshall, C., McGuire, J. L., Lindsey, E. L., Maguire, K. C., Mersey, B., \& Ferrer, E. A. (2011). Has the earth's sixth mass extinction already arrived? Nature, 471(7336): $51-57$.

Burkholder, J., Libra, B., Weyer, P., Heathcote, S., Kolpin, D., Thorne, P. S., \& Wichman, M. (2007). Impact of waste from concentrated animal feeding operation on water quality. Environmental Health Perspectives, 115(2): 308-312.

Food and Agriculture Organization of the United Nations. (2006). Livestock's long shadow: Environmental issues and options. Food and Agriculture Organization of the United Nations, Rome, Italy.

Heederik, D., Sigsgaard, T., Thorne, P. S., Kline, J. N., Avery, R., Bønløkke, J. H., Chrischilles, E. A., Dosman, J. A., Duchaine, C. Kirkhorn, S. R., Kulhankova, K., \& Merchant, J. A. (2007). Health effects of airborne exposures from concentrated animal feeding operations. Environmental Health Perspectives, 115(2): 298-302.

Henning, B. (2011). Standing in livestock's "long shadow": The ethics of eating meat on a small planet. Ethics \& the Environment, 16(2): 63-93.

Ilea, R. C. (2009). Intensive livestock farming: Global trends, increased environmental concerns, and ethical solutions. Journal of Agricultural \& Environmental Ethics, 22(2): 153-167. 
Koneswaran, G., and Neirenberg, D. (2008). Global farm animal production and global warming: Impacting and mitigating climate change. Environmental Health Perspectives, 116(2): 578-582.

Kump, L. R., Kasting, J. F., Crane, R. G. (2010). The Earth System. Pearson Education, Inc. Upper Saddle River, N.J., 321-327, 364-372.

Mallin, M. A., \& Cahoon, L. B. (2003). Industrialized animal production - a major source of nutrient and microbial pollution to aquatic ecosystems. Population and Environment, 24(5): 369-385.

Mann, M. E., \& Kump, L. R. 2009. Dire Predictions: Understanding Global Warming. Pearson Education, Inc. New York, NY.

Mirabelli, M. C., Wing, S., Marshall, S.W., \& Wilcosky, T. C. (2006). Race, poverty and potential exposure of middle-school students to air emissions from confined swine feeding operations. Environmental Health Perspectives, 114(4): 591-596.

Patel, P., \& Centner, T. J. (2010). Air pollution by concentrated animal feeding operations. Desalination and Water Treatment, 19(1-3): 12-16.

Pluhar, E. B. (2010). Meat and morality: Alternatives to factory farming. Journal of Agricultural \& Environmental Ethics, 23(5): 455-468.

Primack, R. B. (2010). Essentials of Conservation Biology. Sinauer Associates, Inc. Sunderland, MA.

Woodruff, D. S. (2001). Declines of biomes and biotas and the future of evolution. Proceedings of the Nation Academy of Sciences of the United States of America, 98(10): 54715476.

ECJ Volume 2, No. 1, 2012 